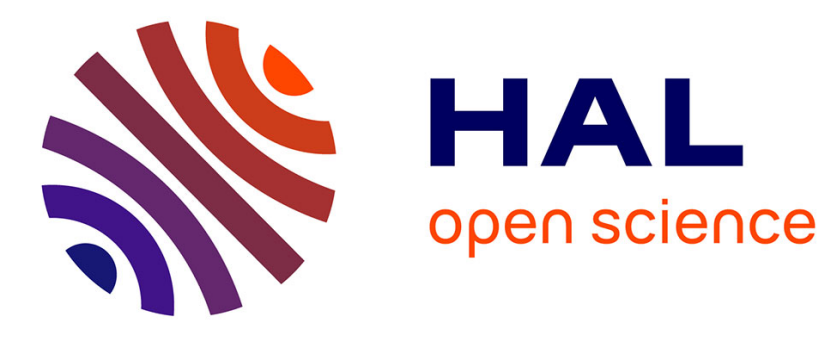

\title{
Isovaleraldehyde degradation using UV photocatalytic and dielectric barrier discharge reactors, and their combinations
}

Jordi Palau, Aymen Amine Assadi, Josep M Penya-Roja, Abdelkrim Bouzaza, Dominique Wolbert, Vicente Martínez-Soria

\section{To cite this version:}

Jordi Palau, Aymen Amine Assadi, Josep M Penya-Roja, Abdelkrim Bouzaza, Dominique Wolbert, et al.. Isovaleraldehyde degradation using UV photocatalytic and dielectric barrier discharge reactors, and their combinations. Journal of Photochemistry and Photobiology A: Chemistry, 2015, 299, pp.110 - 117. 10.1016/j.jphotochem.2014.11.013 . hal-01091351

\section{HAL Id: hal-01091351 \\ https://hal-univ-rennes1.archives-ouvertes.fr/hal-01091351}

Submitted on 5 Dec 2014

HAL is a multi-disciplinary open access archive for the deposit and dissemination of scientific research documents, whether they are published or not. The documents may come from teaching and research institutions in France or abroad, or from public or private research centers.
L'archive ouverte pluridisciplinaire HAL, est destinée au dépôt et à la diffusion de documents scientifiques de niveau recherche, publiés ou non, émanant des établissements d'enseignement et de recherche français ou étrangers, des laboratoires publics ou privés. 
Isovaleraldehyde degradation using UV photocatalytic and dielectric barrier discharge reactors, and their combinations

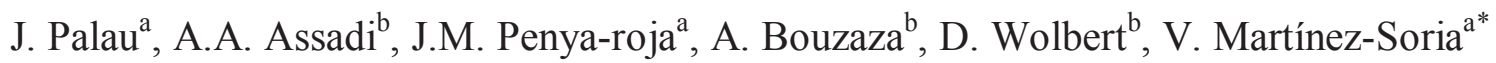

${ }^{a}$ Research Group $\mathrm{GI}^{2} \mathrm{AM}$, Department of Chemical Engineering, University of Valencia, Avda. Universitat s/n, 46100 Burjassot, Valencia, Spain.

${ }^{\mathrm{b}}$ Laboratoire Sciences Chimiques de Rennes - Équipe Chimie et Ingénierie des Procédés, UMR CNRS, ENSCR, Avenue du Général Leclerc, 35700 Rennes, France

*Corresponding author: Vicente Martínez-Soria

E-mail:vmsoria@uv.es

Tel: +34963543169

Fax: +3496354898

\section{Highlights}

- Langmuir-Hinselwood model fitted isovaleraldehyde UV photocatalytic degradation

- Operational parameters were studied in DBD treatment of isovaleraldehyde

- Coupled system provided a synergic improvement in the removal efficiency

- Sequence of reactors affected significantly to degradation efficiency of VOC 


\begin{abstract}
The abatement of isovaleraldehyde present in air was carried out in UV photocatalytic and dielectric barrier discharge reactors (and their combinations) for concentrations up to $150 \mathrm{mg}$ $\mathrm{C} \mathrm{m}^{-3}$ and air flow rates ranging from 4 to $10 \mathrm{~m}^{3} \mathrm{~h}^{-1}$. A kinetic study was performed following a Langmuir-Hinshelwood model. Photocatalytic treatment of an isovaleraldehyde and isovaleric acid mixture showed a clear inhibition of isovaleric acid abatement in presence of isovaleraldehyde. Dielectric barrier discharge treatment of isovaleraldehyde showed an increase of removal efficiency with applied voltage and a decrease with air flow rate and inlet concentration. Moreover, introduction of a catalyst into the dielectric barrier discharge reactor did not produce a significant effect (UV light off). However, a combination of both techniques significantly increased isovaleraldehyde removal efficiency, indicating the treatment technique sequence had an effect on system performance. In conclusion, combined treatment showed promising results for the removal of VOCs, providing a synergic improvement in the removal of isovaleraldehyde.
\end{abstract}




\section{Introduction}

The harmful effects of pollution on the environment and health has led in recent decades and in many countries, to environmental policies aimed at the reduction of pollution (including air pollution) $[1,2]$. Among the main air pollutants are volatile organic compounds (VOCs) released into the atmosphere due to various human activities, among which industrial activity accounts for a high percentage of the total emissions. Long periods of exposure to certain VOCs are linked to the development of cancer, eye irritation and breathing difficulties after short periods of contact.

VOCs are active in many atmospheric reactions contributing to the generation of tropospheric ozone and resulting in environmental problems $[3,4]$. It is therefore necessary to reduce emissions, or if reduction is not possible, treatment with economically and environmentally-sustainable technologies. For this purpose, photocatalytic and dielectric barrier discharge (DBD) treatments are innovative techniques that have advantages (such as a reduced environmental impact) over conventional techniques, however more studies are necessary to develop/implement their industrial applications to make them viable alternatives to existing treatment technologies [5-7].

Heterogeneous photocatalysis is promoted by direct/indirect absorption of a photon with energy equal to or greater than the band gap of the semiconductor (typically $\mathrm{TiO}_{2}$ ), generating a hole $\left(\mathrm{h}^{+}\right)$- electron $\left(\mathrm{e}^{-}\right)$pair, which in turn produce species such as superoxide and hydroxyl radicals $\left(\mathrm{OH}^{*}\right)$ that can oxidize the VOCs to non-toxic end-products (primarily $\mathrm{CO}_{2}$ and water) [8-10].

DBD uses an electrical discharge to treat gas present between electrodes separated by a dielectric material, which can ionize the gas, modifying the components. This generates an electrical breakdown in which the new species create an electronic cascade generating a large number of reactive species (mainly $\mathrm{O}_{2}{ }^{-}, \mathrm{OH}^{-}$and $\mathrm{O}_{3}$ ) which interact and degrade organic 
compounds. This approach has gained increasing attention in recent years, and several researchers have studied this technology for use in the removal of nitrogen oxides, sulphur oxides and VOCs [11-14].

Although several studies have combined non-thermal plasma with heterogeneous catalysis in the abatement of VOCs and nitrogen oxides, the combination of dielectric barrier discharge with photocatalysis using external ultraviolet (UV) radiation in the removal of VOCs has not been extensively explored [15]. Increased removal efficiency for various VOCs [16-18] has been described using this specific combination, however additional efforts are needed to explore the synergistic reactions, as the effects of plasma-triggered photocatalysis are not well understood.

Isovaleraldehyde and isovaleric acid (acid form) are used as reagents in the production of pesticides (e.g. pinacolone) and a wide range of pharmaceutical products, such as butizide [19]. Although isovaleraldehyde is not very toxic, it can cause health and environmental problems. This compound produces oral, dermal and respiratory irritation after exposure as well as discomfort related to the strong odour, even at very low concentrations $[20,21]$. Despite these issues, studies on the removal of isovaleraldehyde from emissions are limited [17].

In a previous work [22], operational parameters such as geometry, UV radiation, humidity, and air gap were explored in the photocatalytic degradation of isovaleraldehyde, and the optimal operational conditions were used in this present work. A part of the present work adds to previous photocatalytic studies by evaluating reaction kinetics in addition to the inhibitory effects of isovaleric acid in the mixture. The main objective of this paper was the degradation of isovaleraldehyde using photocatalysis and dielectric barrier discharge (and their combinations) to determine the potential synergy between systems, the effects on the reactor performance as well as the sequence for applying the techniques. 


\section{Material and methods}

\subsection{Photoreactor unit}

The reactor (with a planar geometry, $1000 \times 135 \times 135 \mathrm{~mm}$ ) consisted of a rectangular polymethyl metracrylate (PMMA) chamber containing two parallel PMMA sheets (4 mm thick) where the distance between sheets could be adjusted to modify the space/air gap (GAP, 30 and $40 \mathrm{~mm}$ ). In the centre of the reactor, four UV-A lamps (PL-S 9W/10/4P, spectrum centred at $365 \mathrm{~nm}, 0.012 \mathrm{~m}$ bulb diameter, $0.135 \mathrm{~m}$ bulb length, from Phillips, Netherlands) were equidistantly distributed to ensure a good distribution of radiation. The light intensity (20 $\mathrm{W} \mathrm{m}^{-2}$ for 4 lamps with $40 \mathrm{~mm}$ of GAP) was measured using a UV Radiometer (VLX3W equipped with a sensor CX 365, ALYS Technologies, Switzerland). The catalyst was placed in commercial fiberglass tissue (Ahlostrom, Finland) supporting $13 \mathrm{~g} \mathrm{~m}^{-2} \mathrm{TiO}_{2}$ at its surface [23] with a total length of $0.8 \mathrm{~m}$, which was located on the internal face of the two PMMA sheets, yielding a photocatalytic surface of $0.19 \mathrm{~m}^{2}[22,24]$.

\subsection{Dielectric barrier discharge reactor}

The DBD reactor employed the same external frame as the photocatalytic unit, containing two sheets of glass installed parallel to each other which supported the electrodes and dielectric barrier. As in the photocatalytic reactor, the distance between sheets was adjustable. Non-thermal plasma was obtained by applying a sinusoidal high voltage between 0-60 $\mathrm{kV}$ (peak to peak) with a frequency of $50 \mathrm{~Hz}$ to the electrodes and a $700 \mathrm{pf}$ capacitator was connected in series with the reactor to determine the charge transferred to the system (Manley method). The voltage applied and the high voltage capacity were measured by highvoltage probes and recorded with a digital oscilloscope (Wave surfer 24Xs, $200 \mathrm{Mhz}$, LeCroy, EEUU) [24]. 


\subsection{Integrated system}

The integrated reactor contained stacked elements for both technologies, using the dielectric barrier discharge reactor as the primary structure with the ultraviolet lamps installed in the centre of the reactor. The fiberglass/catalyst was placed on the inner face of the two glass sheets, between the glass sheet and the inner electrode.

\subsection{Experimental set-up}

Figure 1 shows a diagram of the system used. The air flowrate (air relative humidity of 5\%) was regulated by a mass flow controller (EL-FLOW F-201AV, Hi-Tec Bronkhorst, Netherlands) reaching a maximum working value of $10 \mathrm{~m}^{3} \mathrm{~h}^{-1}$. The humidity of the air stream was regulated to avoid the influence of this parameter on the results $(40 \% \pm 15 \%)$. This was achieved by passing a fraction of the air stream through a countercurrent humidifier column. The volatile organic compound was injected into the inlet air through a syringe pump with manual refill and a volume of $5 \mathrm{~mL}$.

Before every experiment, the power was turned off (UV and/or electric discharge), and once inlet and outlet concentration of VOCs were the same (adsorption equilibrium state), the reactor power was turned on. Output samples were collected at 30 to 60 minute intervals until a steady state was achieved. At the conclusion of the experiment, the reactor was cleaned by a flow of clean air for at least one hour.

VOC concentration and air flow rate were $10-150 \mathrm{mg} \mathrm{C} \mathrm{m}^{-3}$ and from 4-10 $\mathrm{m}^{3} \mathrm{~h}^{-1}$, respectively. 
The operational conditions/parameters used for the experimental series as well as the evaluation of photoreactor performance were:

- Inlet $\left(\mathrm{C}_{\text {inlet }}\right)$ and outlet $\left(\mathrm{C}_{\text {outlet }}\right)$ concentration of pollutant, as milligrams of carbon per cubic meter $\left(\mathrm{mg} \mathrm{C} \mathrm{m}{ }^{-3}\right)$

- Effective volume of reactor $\left(\mathrm{V} ; \mathrm{m}^{3}\right)$ and air flowrate $\left(\mathrm{Q} ; \mathrm{m}^{3} \mathrm{~h}^{-1}\right)$

- $\quad$ Removal efficiency $(\mathrm{RE} ; \%)=100\left(1-\mathrm{C}_{\text {outlet }} / \mathrm{C}_{\text {inlet }}\right)$

- Inlet load (IL; $\mathrm{mg} \mathrm{C} \mathrm{m}^{-3} \mathrm{~s}^{-1}$ ) $=\mathrm{C}_{\text {inlet }} \mathrm{Q} / \mathrm{V}$

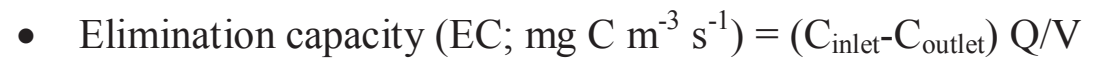

\subsection{Analytical methods}

Isovaleraldehyde and isovaleric acid concentrations were determined by a gas chromatograph (GC Thermo Focus, USA) equipped with a flame ionization detector and a Chrompact FFAP-CD capillary column (25 m of length), with nitrogen gas as the carrier. Samples were collected with a $250 \mu \mathrm{L}$ syringe.

Although intermediate organic compounds such as acetone or acetic acid [22] could be expected as by-products in these processes, they were not found above the detection limit of the analytical method $\left(>0.2 \mathrm{mg} \mathrm{C} \mathrm{m}^{-3}\right)$, at least at the tested operational conditions. A simple pathway for the VOC removal is proposed as follow:

$$
\text { VOC } \rightarrow \text { (intermediates } \rightarrow \text { ) } \mathrm{CO}_{2}+\mathrm{H}_{2} \mathrm{O}
$$

3. Results and discussions

3.1 Photocatalytic reactor

3.1.1 Effects of inlet concentration and flow rate on VOC degradation 
The effects of inlet concentration and flow rate on the performance of the planar photoreactor were tested, and the removal efficiency (RE) of the isovaleraldehyde is shown (Figure 2) for different air flow rates and inlet concentrations. RE decreased when inlet concentration increased, and could be explained by taking into account the limited number of active sites on the catalyst surface available for adsorption and reaction with VOCs [25-27]. Data indicated the higher air flow fed to the reactor, the lower the RE [28], which could be attributed to decreased contact time between the compound and active centres-hydroxyl radicals. The difference was greater at low concentrations and reduced at high concentrations, and could be explained by the ratio between the limited number of active centres and the compound molecules to be degraded decreasing with the inlet concentration of pollutant. At high inlet concentrations, the reaction rate, which determined the number of molecules degraded in a given time, became constant and independent of the inlet concentration (as can be observed and discussed in the next section).

\subsubsection{Photocatalytic degradation of individual compounds: effect of inlet load and kinetics}

Figure 3 shows the elimination capacity (EC) versus the inlet load (IL) for isovaleraldehyde and isovaleric acid. No significant differences in behaviour were observed at different air gaps and air flow rates (Fig 3a) for isovaleraldehyde degradation, which was similar to results previously described for aromatic and oxygenated compounds [29]. For both compounds, a nearly complete elimination (RE $>90 \%$ ) was observed for low IL values, while at high inlet loads, the EC remained relatively constant at a maximum EC of $12 \mathrm{mg} \mathrm{C}$ $\mathrm{m}^{-3} \mathrm{~s}^{-1}$ for isovaleraldehyde and 10-14 $\mathrm{mg} \mathrm{C} \mathrm{m}^{-3} \mathrm{~s}^{-1}$ for isovaleric acid. These values were comparable to those obtained previously in the removal of toluene and xylene [29]. 
The photocatalytic process can be modelled by Langmuir-Hinshelwood (LH) kinetics. Assuming the negligible mass transfer effects and considering a plug flow pattern in the reactor, the mass balance through the photocatalytic reactor can be described by the following equation [30]:

$$
\frac{\mathrm{dC}}{\mathrm{d} \zeta}=\mathrm{r}(1)
$$

where $\mathrm{C}$ is the VOC concentration $\left(\mathrm{mg} \mathrm{C} \mathrm{m}^{-3}\right), \mathrm{r}$ is the rate of disappearance for the component ( $\left.\mathrm{mg} \mathrm{C} \mathrm{m}^{-3} \mathrm{~s}^{-1}\right)$ and $\zeta$ the retention time in the system(s).

Considering the variations in oxygen concentration and water vapour in air as negligible while assuming the reaction was the limiting step and the by-products had little or no action on the active adsorption centres, the LH model can be described by the following rate equation [31-34]:

$$
\mathrm{r}=\mathrm{k} \theta=\frac{\mathrm{k} \mathrm{K}_{\mathrm{LH}} \mathrm{C}}{1+\mathrm{k} \mathrm{K}_{\mathrm{LH}} \mathrm{C}}
$$

where $\mathrm{k}$ is the apparent kinetic constant $\left(\mathrm{mg} \mathrm{C} \mathrm{m}^{-3} \mathrm{~s}^{-1}\right), \theta$ is the fraction of active sites being covered by adsorbed reactant and $\mathrm{K}_{\mathrm{LH}}$ is the adsorption constant $\left(\mathrm{m}^{3} \mathrm{mg} \mathrm{C}^{-1}\right)$. Combining both equations yields:

$$
\left[1+\frac{1}{\mathrm{~K}_{\mathrm{LH}} \mathrm{C}}\right] \mathrm{dC}=-\mathrm{k} \zeta
$$

By integrating and rearranging this equation, it follows that:

$$
\frac{\ln \left(\mathrm{C}_{\text {inlet }} / \mathrm{C}_{\text {outlet }}\right)}{\mathrm{C}_{\text {inlet }}-\mathrm{C}_{\text {outlet }}}=\mathrm{kK}_{\mathrm{LH}} \frac{\zeta}{\mathrm{C}_{\text {inlet }}-\mathrm{C}_{\text {outlet }}}-\mathrm{K}_{\mathrm{LH}}
$$


Plotting $\ln \left(\mathrm{C}_{\text {inlet }} / \mathrm{C}_{\text {outlet }}\right) /\left(\mathrm{C}_{\text {inlet }}-\mathrm{C}_{\text {outlet }}\right)$ versus $\zeta /\left(\mathrm{C}_{\text {inlet }}-\mathrm{C}_{\text {outlet }}\right)$ should be linear if the LH model described the process, where the slope of the regression line represented the product of constants $\mathrm{kK}_{\mathrm{LH}}$ and the $\mathrm{y}$-intercept $-\mathrm{K}_{\mathrm{LH}}$. The correlation between experimental results for the two compounds according to the LH model are shown in Figure 4, and constant values and correlations obtained for the LH model are shown in Table 1.

As can be seen in Table 1, no significant differences were observed for the kinetic constant for isovaleraldehyde although this rate constant $(\mathrm{k})$ should be slightly higher for the lower air gap, since this parameter should influence the light irradiance [22]. The adsorption Langmuir constant $\left(\mathrm{K}_{\mathrm{LH}}\right)$ refers to the adsorption/desorption equilibrium and it is supposed to be independent of the light intensity during photocatalytic reaction. Nevertheless, it has been reported that there are some influence of the photon flow on both kinetic and the apparent adsorption constant [22]. Explanations for this behaviour were related with the hypothesis that irradiation influences adsorption equilibrium and therefore $\mathrm{K}_{\mathrm{LH}}$ values. In any case, the expected variation of the LH model constants due to the variation of irradiation is lower than the experimental error of the test of our study (Table 1).

\subsubsection{Photocatalytic degradation of the mixture}

For these experiments, a mixture of isovaleraldehyde and isovaleric acid (2:1 weight) was added to air, simulating industrial emissions. In Table 2, the individual REs of each compound in the mixture and the overall RE are shown. At the lowest inlet concentrations, the efficacy of both components was similar, but for the highest inlet concentrations (lowest global removal efficiency), the behaviour changed dramatically. As inlet concentration increased, the degradation of isovaleric acid rapidly decreased, and no degradation was observed at inlet concentrations higher than $70 \mathrm{mg} \mathrm{C} \mathrm{m}^{-3}$. At the highest concentrations, isovaleraldehyde was the only compound degraded and was responsible for the overall RE in 
the mixture. These observations may be explained by competition for active centres between these compounds.

Figure 5 shows the variations in EC versus inlet load for isovaleraldehyde and isovaleric acid, individually and as part of a mixture. Results seen for isovaleraldehyde were similar alone or as part of a mixture, and only at the highest concentrations, was the mixture EC slightly lower (compared to the sole compound), suggesting a slight inhibitory effect resulting from competition between both compounds for active sites on the catalyst. In case of isovaleric acid, the behaviour was very different for the individual compound compared to the mixture. Figure 5 shows the EC of isovaleric acid in the mixture decreased drastically with the inlet load, suggesting the compound might be strongly inhibited by the presence of the isovaleraldehyde, which agrees with the adsorption constant values for both compounds. The $\mathrm{K}_{\mathrm{LH}}$ values for isovaleraldehyde were higher than those of isovaleric acid, and it could be assumed that most of the catalyst active centres were preferentially occupied by isovaleraldehyde, hindering (to some extent) the adsorption of the isovaleric acid and its degradation. Similar competitive adsorption phenomena are described in the literature [29, 35].

\subsection{Dielectric barrier discharge reactor}

\subsubsection{Effects of inlet concentration and air gap}

Isovaleraldehyde removal efficiency for the DBD reactor at different operational conditions can be seen in Figure 6. As was expected, RE decreased with concentration and increased with applied voltage [7], which could be explained by a ratio reduction between the number of radicals and the energy electrons available per unit of VOC to be degraded under constant conditions [36]. Moreover, the increased removal efficiency observed when the applied voltage was increased, resulted from an increased number of radicals and electrons 
available in the system $[11,37]$.

The effect of distance between the sheets (GAP) that support the electrodes can be seen in Figure 6, where the results of experiments performed at $17 \mathrm{kV}$ and at similar inlet

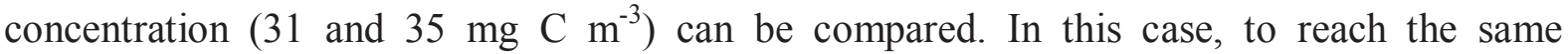
residence time of $1.3 \mathrm{~s}$, the GAP was reduced from 40 to $30 \mathrm{~mm}$ and the flow rate was changed from 10 to $8 \mathrm{~m}^{3} \mathrm{~h}^{-1}$. A reduction in distance between electrode sheets resulted in an increased RE (17 to 29\%), suggesting better ionization of the air due to increased contact between air and plasma. This observation was supported by the work of Cal and Schluep [38], that studied two different gap distances $(3$ and $5 \mathrm{~mm}$ ) between electrodes and observed that the reactor with the $5 \mathrm{~mm}$ gap spacing required about three times the amount of power compared to the reactor with the $3 \mathrm{~mm}$ gap to achieve a benzene RE of $95 \%$.

\subsubsection{Effect of the presence of $\mathrm{TiO}_{2}$ catalyst in the DBD reactor}

Figure 7 shows the variations in RE with applied voltage for the DBD reactor combined with catalyst sheets in situ. Comparing the results between the two configurations, introduction of the catalyst did not appear to exert a positive effect on the RE of isovaleraldehyde, also seen for similar catalysts elsewhere [39]. These results suggest the ultraviolet light produced by the ion plasma was not enough to appreciably activate the $\mathrm{TiO}_{2}$ particles and create sufficient paired hole-electrons which could contribute (significantly) to the oxidation of VOCs [15]. Moreover, the slightly lower RE values for DBD combined with catalyst at low voltage $(<20 \mathrm{kV})$ could be attributed to an extra-resistance due to the introduction of the $\mathrm{TiO}_{2}$ sheets. In contrast, other researchers report different results, 
indicating higher removal efficiencies for DBD combined with catalyst, which could be due to modification of the catalysts by the incorporation of metals (such as aluminium or silver), resulting in significant changes in catalytic behaviour [40-42].

\subsection{Performance of the combined system}

The performance of the combined system and its comparison with DBD and photocatalytic reactors is shown in Figure 8. These experiments were carried out at an inlet concentration of isovaleraldehyde around $50 \mathrm{mg} \mathrm{C} \mathrm{m}^{-3}$, an applied voltage of 12,17 and 20 $\mathrm{kV}$, flow rates of 4,6 and $10 \mathrm{~m}^{3} \mathrm{~h}^{-1}$ and an electrode gap of $30 \mathrm{~mm}$ (the $0 \mathrm{kV}$ voltage corresponded to the operation of the photocatalytic reactor alone). As expected, RE increased for both systems with applied voltage, and was attributed to an increase in the total number of free radicals and high-energy electrons. Additionally, RE decreased with flow rate due to decreased contact time with ionized molecules, free radicals, high-energy electrons and the catalyst. Furthermore, the existence of a threshold voltage $(\sim 10 \mathrm{kV})$ was seen, where below this value, electric breakdown did not occur and the pollutant was not degraded by DBD. The $\mathrm{RE}$ of the combined system was considerably higher than the REs obtained for individual reactors (photocatalyst and DBD) (Figure 8).

The values of the elimination capacities obtained for combined and individual reactors are summarized in Table 3. As can be seen, the EC of the combined system was considerably higher $(>10-20 \%)$ than the sum obtained for individual reactors and independent of the applied voltage (12 or $17 \mathrm{kV})$. This indicated that coupling of the photocatalytic and DBD reactors significantly improved elimination and, consequently, the energy efficiency. 
Studies using a combination of these technologies have been performed [16, 43, 44], and the results obtained by coupling these techniques show an improvement in elimination and a significant decrease in the production of by-products. The explanations of this synergistic effect have been attributed to diverse causes. It has been linked to intermediates produced by DBD [44] which could be more easily degraded by photocatalysis than the original compounds, increasing the rate of degradation for the overall system. This hypothesis was confirmed by analysis of the compounds adsorbed on the hole-electron pairs. In another study [15], the improvement in the RE was linked to improvements in VOC degradation by the photocatalytic phase, where the free radicals, oxygen atoms and ozone molecules produced by DBD interact with catalyst and the pollutants [16].

\subsubsection{Effect of the treatment sequence}

In order evaluate the effects of treatment sequence on RE, experiments were designed where the reactor was internally divided into halves. DBD was implemented in one half while the other half was operated as a combined DBD and photocatalytic reactor. Initially, experiments were performed using DBD treatment first, then combined (DBD / Photo + DBD) and the sequence reversed (Photo + DBD / DBD). Analyses of each half-reactor were carried out. Results were also compared to the full reactor operating with both technologies.

Figure 9 shows the RE values obtained for the three combinations. As expected, when the operation was performed with both technologies in the complete reactor, the performance was higher than when half the reactor operated with DBD. This result was consistent with the positive combination of these technologies (described above). When both sequential configurations were compared, for any voltage applied, higher removal efficiencies were 
obtained when DBD treatment was placed in the first half, which could indicate treatment with this technique promoted/increased the rate of photocatalytic degradation in the second part. The results obtained from the first sequential reactor design (DBD alone and combined as DBD/Photo + DBD, second column of Figure 9) showed that degradation of the compound in the first part of the system contributed near the half of the global removal efficiency, and as voltage increased, the contribution percentage decreased (the combined portion increased the contribution of the applied voltage). The behaviour of the second sequential reactor (Photo + DBD / DBD, first column in Figure 9) was quite different, where the removal contribution from the first part of the reactor (combined) was notably higher than the second portion (DBD alone), except at the lowest voltage applied.

These results could be explained by assuming pretreatment with DBD could enhance photocatalytic activity. Several reasons have been proposed in the literature for this enhancement [41]. By combining both treatments, modifications in electron energy, the type of discharge and effects on catalytic properties occur. The presence of the catalyst in the plasma discharge could increase the production of active species, in some cases accelerating the formation of superoxide $\left(\mathrm{O}_{2}^{-}\right)$, reducing the recombination process and increasing total catalytic activity. Furthermore, the plasma could generate intermediate species with longer life-times which interacted with the surface of the catalyst (ozone, atomic oxygen and other reactive species) and increased the catalytic activity of the reactor. Moreover, the discharge could affect catalyst properties, improving the dispersion of the active catalytic components by modifying the stability and catalytic activity of the material. It is important to note the adsorption process for organic compounds was positively influenced by the presence of plasma discharge, and improved the affinity of the catalyst for the organic compounds. Furthermore, reactions could occur through alternative reduction and oxidation at the surface of the catalyst, and a positive effect for heat activation by the dielectric barrier discharge. 


\section{Conclusions}

The application of photocatalytic treatment to degrade VOCs resulted in a maximum elimination capacity of around 12 and $14 \mathrm{mg} \mathrm{C} \mathrm{m}^{-3}$ for isovaleraldehyde and isovaleric acid, respectively. The elimination capacity of isovaleric acid was negatively affected in presence of isovaleraldehyde, indicating inhibitory and competition effects between both compounds.

The dielectric barrier discharge treatment showed an increased removal efficiency when the applied voltage was increased, promoting the generation of high energy electrons and free radicals capable of degrading volatile organic compounds. As expected, an increase in air flow rate and inlet concentration of the VOC resulted in decreased removal efficiency

At tested operational conditions, the coupled system combining dielectric barrier discharge and UV photocatalysis showed a significant improvement in VOC removal efficiency. This suggested the dielectric barrier discharge process promoted degradation of intermediates which facilitated the catalytic reaction, and the energy involved in the coupled system promoted the adsorption of organic compounds at catalytic active sites. The sequence of VOC treatments, dielectric barrier discharge and photocatalysis coupled with dielectric barrier discharge, was important to removal efficiency. The use of dielectric barrier discharge in the first half and in the second half of a coupled reactor system showed higher removal efficiency due to the generation of smaller compounds and more active molecules that could interact in the second half, activating the catalyst sites.

\section{Acknowledgements}

Assadi, Bouzaza and Wolbert gratefully acknowledge the financial support provided by the French National Research Agency (ANR) for this work. Palau, Penya-roja and Martinez-Soria acknowledge financial support from the Ministerio de Educación (Spain, 
Project CTM-2010-15031/TECNO) and Generalitat Valenciana (Spain, Project PROMETEO/2013/053).

\section{References}

[1] Council Directive 1999/13/EC on the limitation of emissions of volatile organic compounds due to the use of organic solvents in certain activities and installations. Official Journal L 85, 29 March 1999, pp. 1-22.

[2] USA EPA (2008) Clean Air Act. US Code, Environmental Protection Agency. Washington DC, 2008.

[3] European Solvent Industry Group, ESIG, http:// http://www.esig.org/en/about-solvents/healthsafety-environment/ozone. Accessed 15th July 2014.

[4] H.J. Bloemen, J. Burn, Chemistry and Analysis of Volatile Organic Compounds in the Environment, Springer, London, 2012.

[5] G.R. Parmar, N.N. Rao, Emerging Control Technologies for Volatile Organic Compounds, Crit. Rev. Env. Sci. Technol. 39 (2009) 41-78.

[6] A.A Assadi A. Bouzaza, D. Wolbert, Photocatalytic oxidation of Trimethylamine and Isovaleraldehyde in an annular reactor: Influence of the Mass Transfer and the relative humidity, J. Photochem. Photobiol., A 236 (2012) 61-69. 
[7] H.M. Lee, M.B. Chang, Abatement of Gas-phase p-Xylene via Dielectric Barrier Discharge, Plasma Chem. Plasma Process. 23 (2003) 541-558.

[8] C.P. Chang, J.N. Chen, M.C. Lu, H.Y. Yang, Photocatalytic oxidation of gaseous DMF using thin film $\mathrm{TiO}_{2}$ photocatalyst, Chemosphere 58 (2005) 1071-1078.

[9] G. Vincent, P.M. Manrique, O. Zahraa, Abatement of volatile organic compounds using an annular photocatalytic reactor: Study of gaseous acetone, J. Photochem. Photobiol., A 197 (2008) 177-189.

[10] J. Jeong, K. Sekiguchi, W. Lee, K. Sakamoto, Photodegradation of gaseous volatile organic compounds (VOCs) using $\mathrm{TiO}_{2}$ photoirradiated by an ozone-producing UV lamp: decomposition characteristics, identifications of by-products and water soluble organic intermediates, J. Photochem. Photobiol., A 169 (2004) 279-289.

[11] H.M. Lee, M.B. Chang, Gas-Phase Removal of Acetaldehyde via Packed-Bed Dielectric Barrier Discharge Reactor, Plasma Chem. Plasma Process. 21 (2001) 329-343.

[12] Z. Chen, V.K. Mathur, Non thermal Plasma for Gaseous Pollution Control, Ind. Eng. Chem. Res. 41 (2002) 2082-2089.

[13] C.H.Subrahmanyam, A. Renken, L. Kiwi-Minsker, Novel catalytic non-thermal plasma reactor for the abatement of VOCs, Chem. Eng. J. 134 (2007) 78-83. 
[14] S.Y. Park, B.R. Deshwal, H.S. Moon, NOx removal from the flue gas of oil-fired boiler using a multistage plasma-catalyst hybrid system, Fuel Process. Technol. 89 (2008) 540-548.

[15] A.M. Vandenbroucke, R. Morent, N. De Geyter, C. Leys C, Non-thermal plasmas for non-catalytic and catalytic VOC abatement, J. Hazard. Mater. 195 (2011) 30-54.

[16] O. Guaitella, F. Thevenet, E. Puzenat, C. Guillard, A. Rousseau, $\mathrm{C}_{2} \mathrm{H}_{2}$ oxidation by plasma/ $\mathrm{TiO}_{2}$ combination: Influence of the porosity, and photocatalytic mechanisms under plasma exposure, Appl. Catal. B 80 (2008) 296-305.

[17] A. Maciuca, C. Batiot-Dupeyrat, J.M. Tatibouët, Synergetic effect by coupling photocatalysis with plasma for VOCs concentration removal from air, Appl. Catal. B 125 (2012) 432-438.

[18] H. Zhang, K. Li, T. Sun, J. Jia, Z. Lou, S. Yao, G. Wang, The combination effect of dielectric barrier discharge (DBD) and $\mathrm{TiO}_{2}$ catalytic process on styrene removal and the analysis of the by-products and intermediates, Res. Chem. Intermed. April (2013) 1-15. http://dx.doi.org/10.1007/s11164-013-1180-6

[19] C. Kohlpaintner, M. Schulte, J. Falbe, P. Lappe, G.D. Frey, Aldehydes, Aliphatic. In: Ullmann's Encyclopedia of Industrial Chemistry, Wiley-VCH, New York, 2013. http://dx.doi.org/10.1002/14356007.a01_321.pub3 
[20] International Programme on Chemical Safety, OECD screening information databases: 3-methyl butanal, Canadian Centre for Occupational Health and Safety, Hamilton, Canada. http://www.inchem.org/documents/sids/sids/590-86-3.pdf Accessed 15 th July 2014.

[21] S.P.P. Ottengraf, Exhaust gas purification, in: H.J. Rhem, G. Reed, (Eds.) Biotechnology, Vol. 8, VCH, Weinheim, 1986.

[22] A.A. Assadi, J. Palau, A. Bouzaza, D. Wolbert, Modeling of a continuous photocatalytic reactor for isovaleraldehyde oxidation: Effect of different operating parameters and chemical degradation pathway, Chem. Eng. Res. Des. 91 (2013) 1307-1316.

[23] Ahlstrom Patent EP 1069950, 2000. AU 735798 US 09/467, 650; JP 2000-542104

[24] A.A. Assadi, J. Palau, A. Bouzaza, J.M. Penya-RojaM, V. Martinez-Soria, D. Wolbert, Abatement of 3-methylbutanal and trimethylamine with combined plasma and photocatalysis in a continuous planar reactor, J. Photochem. Photobiol., A 282 (2014) 1-8 http://dx.doi.org/10.1016/j.jphotochem.2014.03.001

[25] T. Obee, R.T. Brown, $\mathrm{TiO}_{2}$ photocatalysis for indoor air applications: effects of humidity and trace contaminant levels on the oxidation rates of formaldehyde, toluene, and 1,3butadiene, Environ. Sci. Technol. 29 (1995) 1223-1231.

[26] A. Bouzaza, C. Vallet, A. Laplanche, Photocatalytic degradation of some VOCs in the gas phase using an annular flow reactor - determination of the contribution of mass transfer 
and chemical reaction steps in the photodegradation process, J. Photochem. Photobiol., A 177 (2006) 212-217.

[27] S.B. Kim, S.C. Hong, Kinetic study for photocatalytic degradation of volatile organic compounds in air using thin film of a $\mathrm{TiO}_{2}$ photocatalyst, Appl. Catal. B 35 (2002) 305-315.

[28] Jeong J, Sekiguchi K, Lee W, Sakamoto K (2005) Photodegradation of gaseous volatile organic compounds (VOCs) using $\mathrm{TiO}_{2}$ photoirradiated by an ozone producing UV lamp: decomposition characteristics, identification of by-products and water soluble organic intermediates. J Photochem Photobiol A 169:279-287.

[29] J. Palau, J.M. Penya-Roja, C. Gabaldón, F.J. Álvarez-Hornos, F. Sempere,V. MartínezSoria, UV photocatalytic oxidation of paint solvent compounds in air using an annular $\mathrm{TiO}_{2}-$ supported reactor, J. Chem. Technol. Biotechnol. 86 (2010) 273-281.

[30] G.F. Froment, K.B. Bischoff, Chemical Reactor and Design, John Wiley \& Sons, New York, 1979

[31] S. Wang, H.M. Ang, M.O. Tade, Volatile organic compounds in indoor environment and photocatalytic oxidation: state of the art, Environ. Int. 33 (2007) 659-705. http://dx.doi.org/10.1016/j.envint.2007.02.011

[32] K. Demeestere, J. Dewulf, H. Van Langenhove, Heterogeneous photocatalysis as an advanced oxidation process for the abatement of chlorinated, monocyclic aromatic and 
sulfurous volatile organic compounds in air: state of the art, Crit. Rev. Env. Sci. Technol. 37 (2007) 489-509.

[33] W. Wang, Y. Ku, Photocatalytic degradation of gaseous benzene in air streams by using an optical fiber photoreactor, J. Photochem. Photobiol., A 159 (2003) 47-59.

[34] C. Belver, M.J. López-Muñoz, J.M. Coronado, J. Soria, Palladium enhanced resistance to deactivation of titanium dioxide during the photocatalytic oxidation of toluene vapors, Appl. Catal. B 46 (2003) 497-509.

[35] K. Aoki, T. Ohwaki, Y. Taga, Photocatalytic degradation of formaldehyde and toluene mixtures in air with a nitrogen-doped $\mathrm{TiO}_{2}$ Photocatalyst, Chem. Lett. 35 (2006) 616-617.

[36] H. Ma, P. Chen, R. Ruan, $\mathrm{H}_{2} \mathrm{~S}$ and $\mathrm{NH}_{3}$ Removal by Silent Discharge Plasma and Ozone Combo-System, Plasma Chem. Plasma Process. 21 (2001) 661-624.

[37] C.J. Liu, B. Xue, B. Eliasson, F. He, Y. Li, G.H. Xu, Methane Conversion to Higher Hydrocarbons in the Presence of Carbon Dioxide Using Dielectric-Barrier Discharge Plasmas, Plasma Chem. Plasma Process. 21 (2001) 301-310.

[38] M.P. Cal, M. Schluep, Destruction of Benzene with Non-Thermal Plasma in Dielectric Barrier Discharge Reactors, Environ. Prog. 20 (2001) 151-156. 
[39] H.B. Huang, D.Q. Ye, M.L. Fu, F.D. Feng, Contribution of UV light to the decomposition of toluene in dielectric barrier discharge plasma/photocatalysis system, Plasma Chem. Plasma Process. 27 (2007) 577-588.

[40] J. Jarrige, P. Vervisch, Plasma-enhanced catalysis of propane and isopropyl alcohol at ambient temperature on a $\mathrm{MnO}_{2}-$ based catalyst, Appl. Catal. B 90 (2009) 74-82.

[41] J. Van Durme, J. Dewulf, C. Leys, H. van Langenhove, Combining non-thermal plasma with heterogeneous catalysis in waste gas treatment: A review, Appl. Catal. B 78 (2008) 324333.

[42] S. Delagrange, L. Pinard, J.M. Tatibouët, Combination of a non-thermal plasma and a catalyst for toluene removal from air: Manganese based oxide catalysts, Appl. Catal. B 68 (2006) 92-98.

[43] R.B. Sun, Z.G. Xi, F.H. Chao, W. Zhang, H.S. Zhang, D.F. Yang, Decomposition of low-concentration gas-phase toluene using plasma-driven photocatalyst reactor, Atmos. Environ. 41 (2007) 6853-6859.

[44] F. Thevenet, O. Guaïtella, C. Guillard, E. Puzenat, G. Stancu, J. Roepcke, A. Rousseau, Comparison of the Plasma-Photocatalyst Synergy at Low and Atmospheric Pressure, Int. J. Plas. Env. Sci. Tech. 1 (2007) 52-56. 
Figure Captions

Figure 1. Schematics and layout of the integrated system: photocatalytic and DBD reactor.

Figure 2. Isovaleraldehyde conversion versus inlet concentration at different air flow rates and $\mathrm{GAP}=40 \mathrm{~mm}$.

Figure 3. Elimination capacity versus inlet load for isovaleraldehyde (a) and isovaleric acid (b) as individual pollutants.

Figure 4. Regression of experimental results with the kinetic LH model.

Figure 5. Comparison of elimination capacities for isovaleraldehyde (a) and isovaleric acid (b), individually and as a mixture. Inlet concentration of 34-140 $\mathrm{mg} \mathrm{C} \mathrm{m}^{-3}$ and a $4 \mathrm{~m}^{3} \mathrm{~h}^{-1}$ air flow rate. $\mathrm{GAP}=30 \mathrm{~mm}$.

Figure 6. Removal efficiency of the dielectric barrier discharge reactor at different inlet concentrations and applied voltages. a) Residence time $=1.3 \mathrm{~s}$ and a GAP $=40 \mathrm{~mm}, \mathrm{~b}$ ) Residence time $=1.3 \mathrm{~s}$ and $\mathrm{GAP}=30 \mathrm{~mm}$.

Figure 7. Influence of catalyst on RE for various applied voltages. Inlet concentration of isovaleraldehyde $=35 \mathrm{mg} \mathrm{C} \mathrm{m}^{-3}$, air flow rate $=10 \mathrm{~m}^{3} \mathrm{~h}^{-1}$ and $\mathrm{GAP}=40 \mathrm{~mm}$.

Figure 8. RE for dielectric barrier discharge and its combination with photocatalysis for different applied voltages and flow rates. Inlet concentration $=50 \mathrm{mg} \mathrm{C} \mathrm{m} \mathrm{m}^{-3}$ (isovaleraldehyde) and GAP $=40 \mathrm{~mm}$. 
Figure 9. Effect of the treatment sequence for different applied voltages. Inlet concentration = $50 \mathrm{mg} \mathrm{C} \mathrm{m}^{-3}$ (isovaleraldehyde), air flow rate $=8 \mathrm{~m}^{3} \mathrm{~h}^{-1}$ and $\mathrm{GAP}=30 \mathrm{~mm}$.

Table 1. Values and estimated errors for LH model constants (obtained from regression of the experimental results, see Figure 4).

\begin{tabular}{lllll}
\hline VOC & $\mathrm{kK}_{\mathrm{LH}}\left(\mathrm{s}^{-1}\right)$ & $\mathrm{K}_{\mathrm{LH}}\left(\mathrm{m}^{3} \mathrm{mg} \mathrm{C}^{-1}\right)$ & $\mathrm{k}\left(\mathrm{mg} \mathrm{C} \mathrm{m}^{-3} \mathrm{~s}^{-1}\right)$ & $\mathrm{r}^{2}$ \\
\hline Isovaleraldehyde $(40 \mathrm{~mm})$ & $0.374 \pm 0.024$ & $0.037 \pm 0.006$ & $10.1 \pm 2.3$ & 0.93 \\
& & & & \\
Isovaleraldehyde (30 mm) & $0.604 \pm 0.083$ & $0.065 \pm 0.016$ & $9.3 \pm 3.6$ & 0.89 \\
& & & & 0.98 \\
Isovaleric acid (30 mm) & $0.310 \pm 0.017$ & $0.022 \pm 0.002$ & $14.1 \pm 2.1$ &
\end{tabular}

Table 2. Global and individual removal efficiencies (RE\%) in the photocatalytic reactor at different VOC inlet concentrations. Air flow rate $=4 \mathrm{~m}^{3} \mathrm{~h}^{-1}$ and GAP $=30 \mathrm{~mm}$.

\begin{tabular}{cccc}
\hline $\begin{array}{c}\text { Inlet concentration } \\
\left(\mathrm{mg} \mathrm{C} \mathrm{m}^{-3}\right)\end{array}$ & Global RE & Isovaleraldehyde RE & Isovaleric acid RE \\
\hline 34.6 & 34.6 & $(\%)$ & $(\%)$ \\
68.1 & 23.3 & 36.5 & 32.9 \\
104.6 & 10.7 & 33.9 & 12.5 \\
140.6 & 21.4 & 0.0 \\
\hline
\end{tabular}


Table 3. EC ( $\mathrm{mg} \mathrm{C} \mathrm{m}^{-3} \mathrm{~s}^{-1}$ ) values for isovaleraldehyde removal by DBD, photocatalysis and a combination of both. Inlet concentration $=40 \mathrm{mg} \mathrm{C} \mathrm{m}^{-3}$ and $\mathrm{GAP}=40$.

\begin{tabular}{|c|c|c|c|c|}
\hline \multirow{2}{*}{ Applied Voltage } & \multirow{2}{*}{ Reactor } & \multicolumn{3}{|c|}{ Flow-rate } \\
\hline & & $4 \mathrm{~m}^{3} \mathrm{~h}^{-1}$ & $6 \mathrm{~m}^{3} \mathrm{~h}^{-1}$ & $10 \mathrm{~m}^{3} \mathrm{~h}^{-1}$ \\
\hline $0 \mathrm{kV}$ & Photocatalysis & 4.5 & 5.9 & 8.4 \\
\hline \multirow{2}{*}{$12 \mathrm{kV}$} & DBD & 1.8 & 1.9 & 1.5 \\
\hline & Combined & 7.7 & 8.9 & 11.3 \\
\hline \multirow{2}{*}{$17 \mathrm{kV}$} & DBD & 3.5 & 5.2 & 6.0 \\
\hline & Combined & 9.8 & 12.1 & 17.6 \\
\hline
\end{tabular}

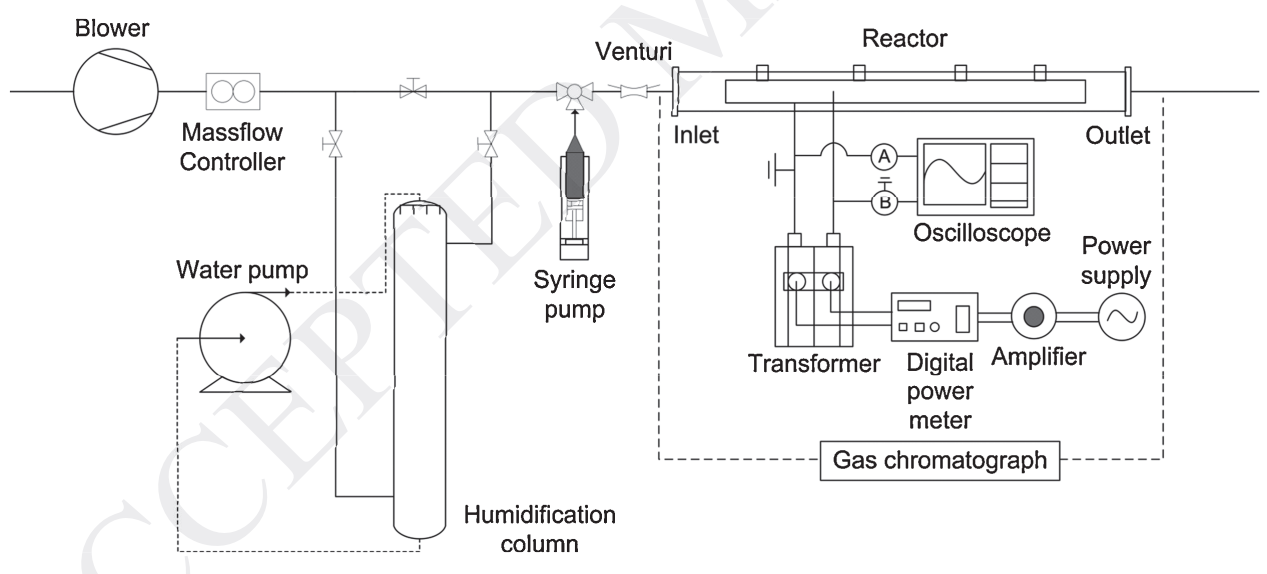

Fig. 1 


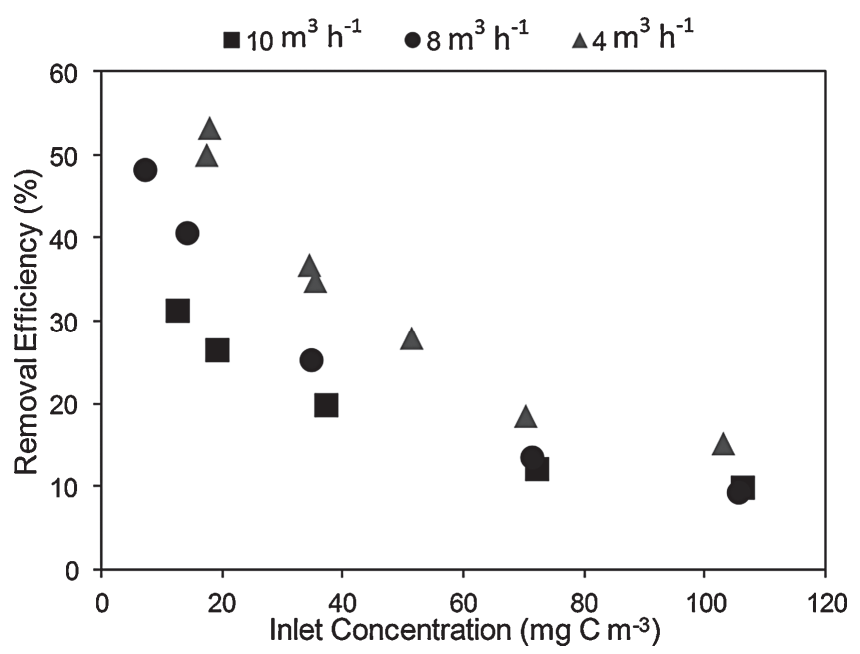

Fig. 2
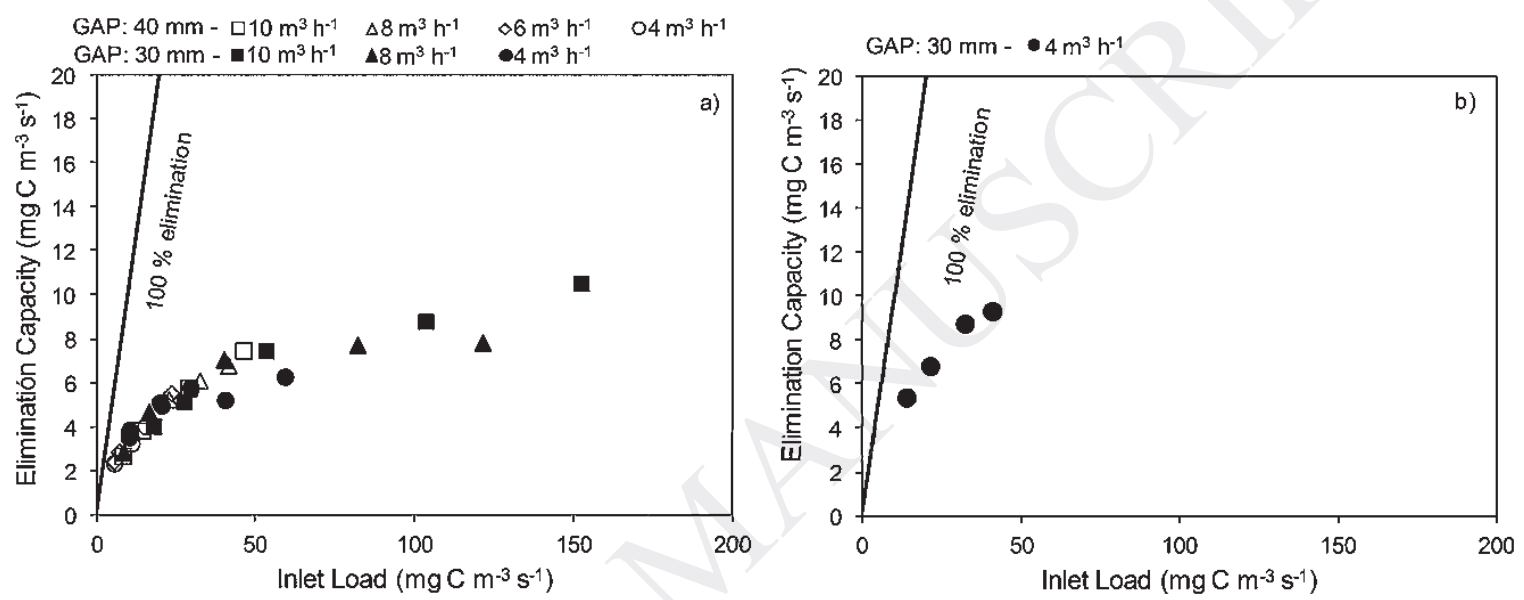

Fig. 3 

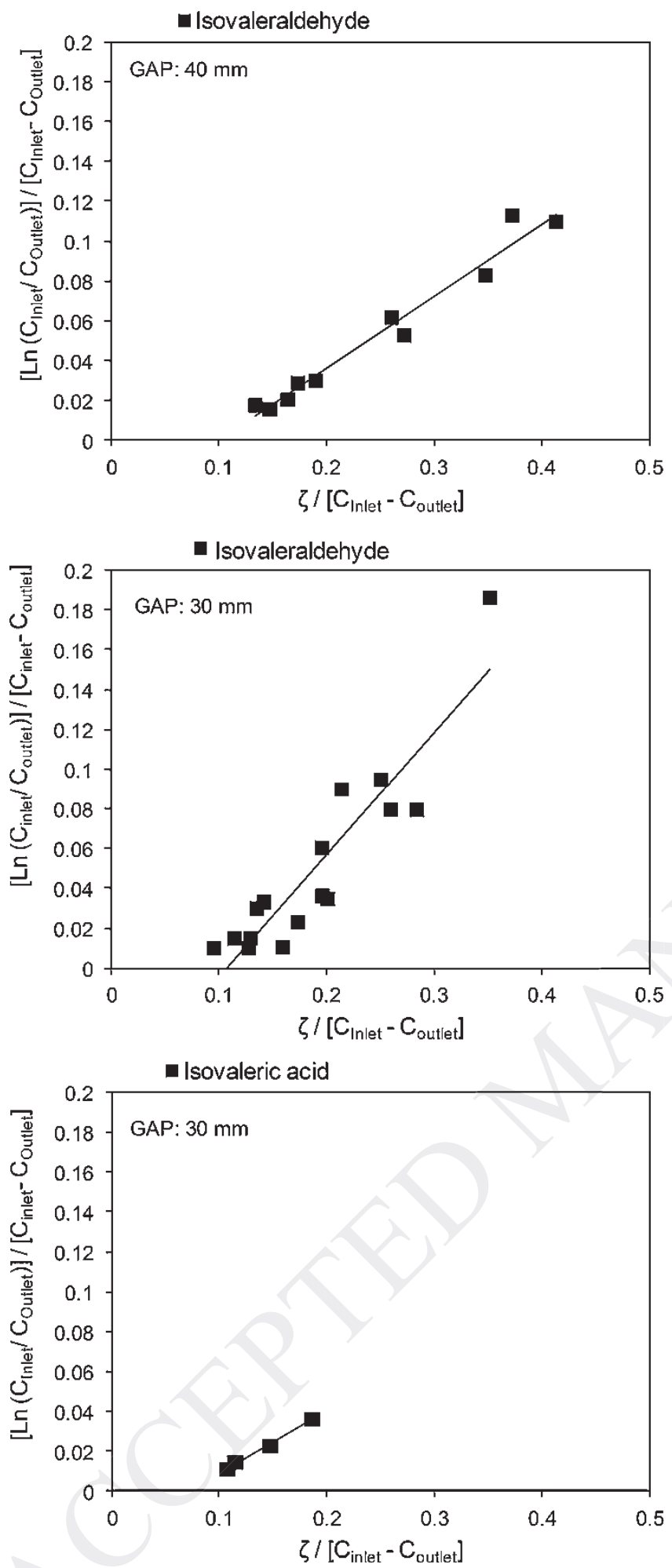

Fig. 4 

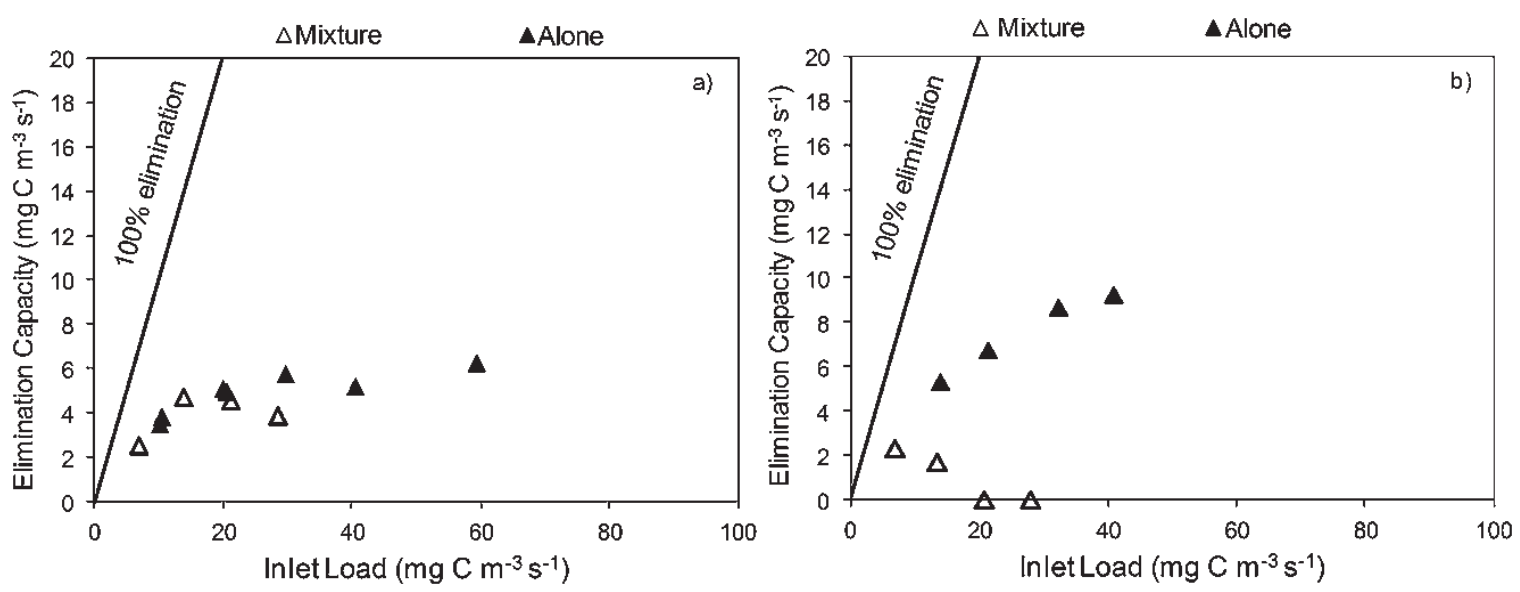

Fig. 5
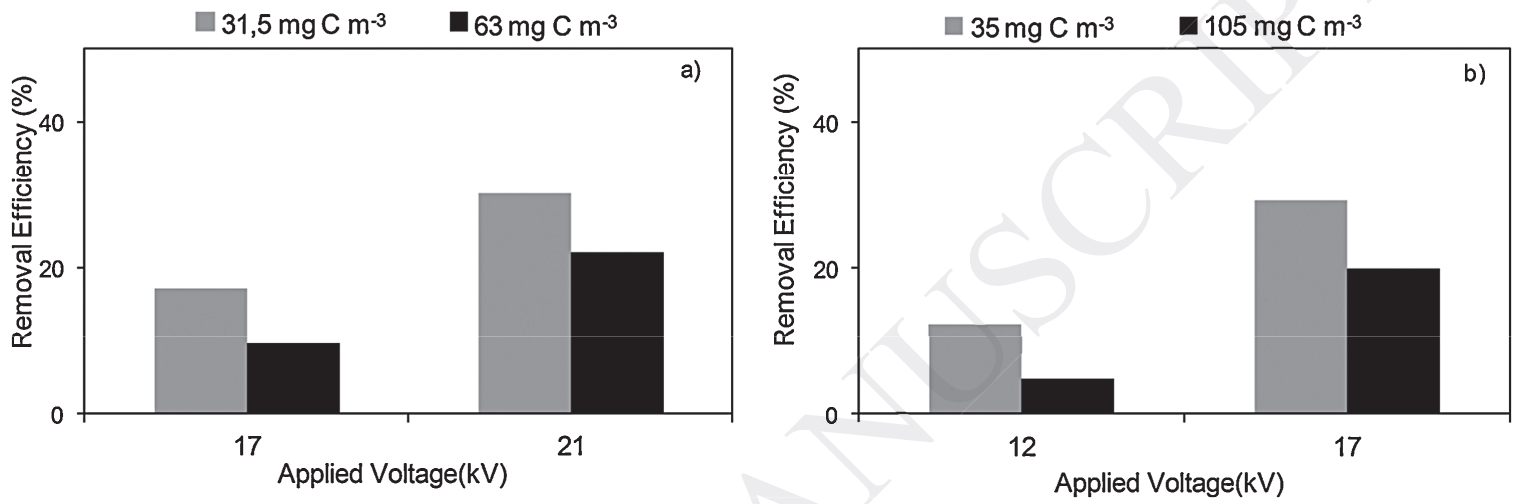

Fig. 6

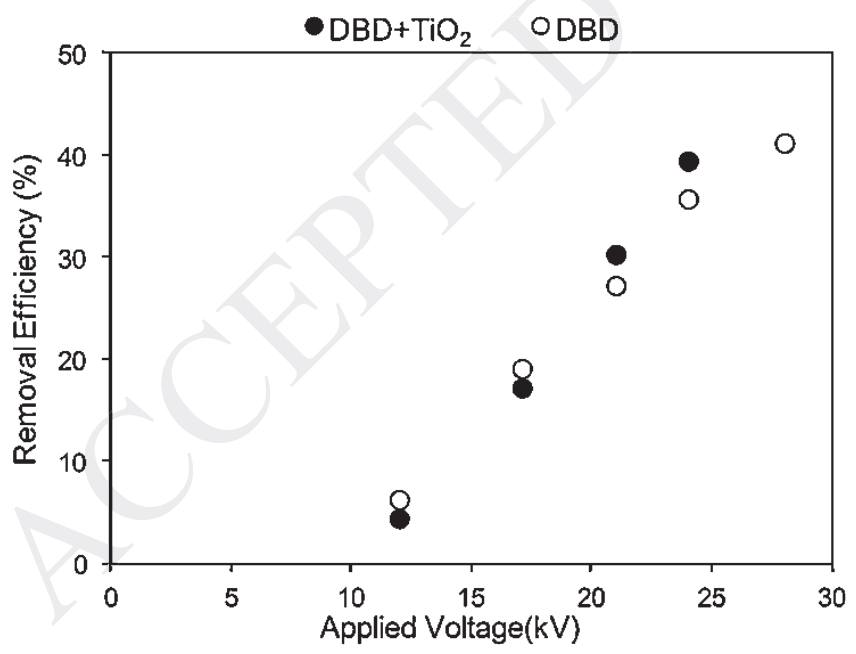

Fig. 7 


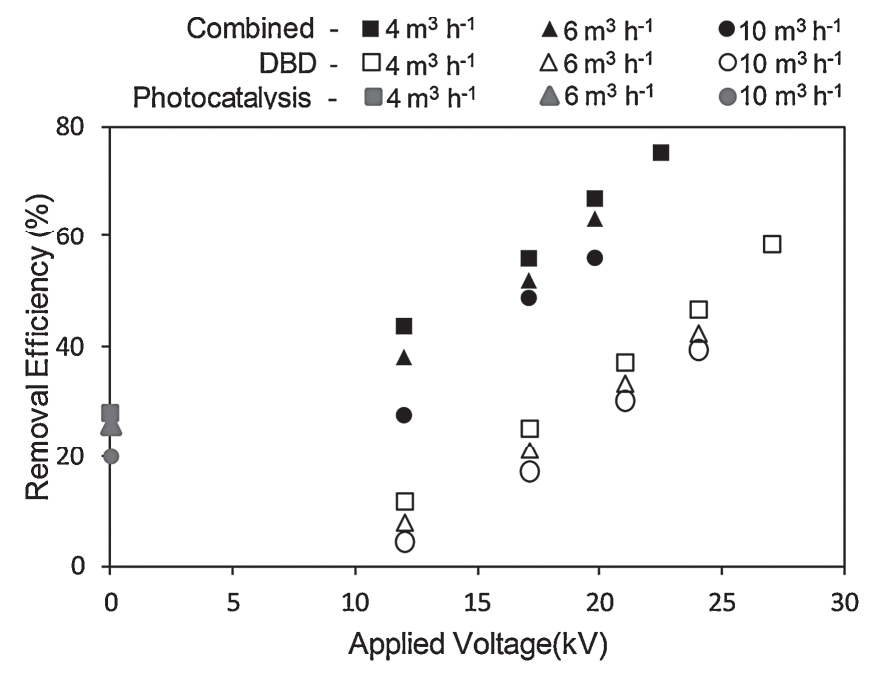

Fig. 8

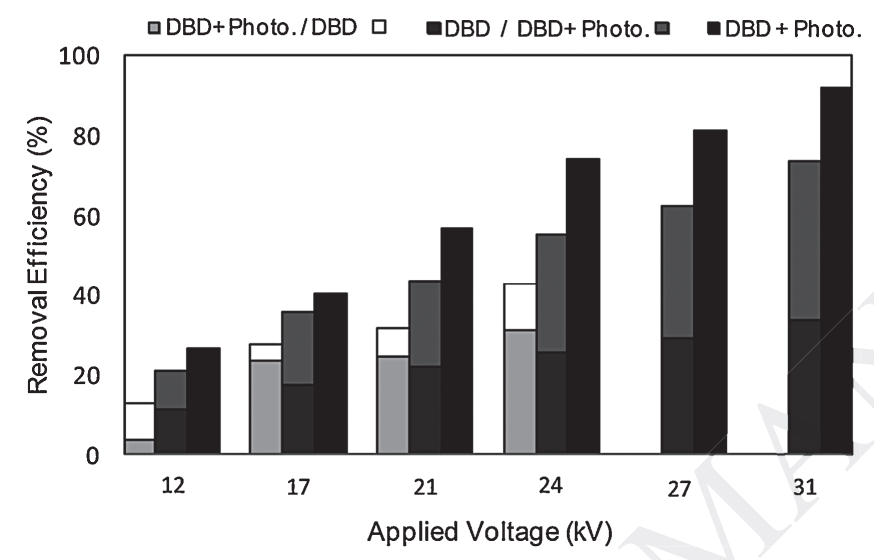

Fig. 9 